City University of New York (CUNY)

CUNY Academic Works

Publications and Research

Hunter College

2012

\title{
Taking Responsibility: The Multiple and Shifting Positions of Social Justice Educators
}

Debbie Sonu

CUNY Hunter College

Rachel Oppenheim

Antioch University

Shira Epstein

CUNY City College

Ruchi Agarwal

San Francisco State University

\section{How does access to this work benefit you? Let us know!}

More information about this work at: https://academicworks.cuny.edu/hc_pubs/278

Discover additional works at: https://academicworks.cuny.edu

This work is made publicly available by the City University of New York (CUNY).

Contact: AcademicWorks@cuny.edu 


\section{Taking responsibility: The multiple and shifting positions of social justice educators}

Education, Citizenship and Social Justice 7(2) 175-189

(c) The Author(s) 2012

Reprints and permission: sagepub.co.uk/journalsPermissions.nav DOI: $10.1177 / 17461979 / 2440855$ esj.sagepub.com

@SAGE

\title{
Debbie Sonu
}

Hunter College, CUNY, USA

\section{Rachel Oppenheim}

Antioch University, USA

\section{Shira Eve Epstein \\ City College, CUNY, USA}

\section{Ruchi Agarwal}

San Francisco State, USA

\begin{abstract}
In this article, we present a qualitative multi-case study of three beginning elementary teachers working in New York City and describe the distinct ways in which each articulates her responsibility to teach a social justice-oriented education. We employ positioning theory to examine how teachers narrate their relationship to the concept of social justice and how this relates to the ways in which they identify themselves and others as capable and qualified to engage in such work. We find that responsibility to teach for social justice is often delegated based on a perception of experiences with injustice and wonder how this rigid outlook can be made more malleable and inclusive. We draw from the work of Sharon Todd to imagine how individuals, situated within unique and divergent circumstances, can all be framed as integral members in the making of a more just world. This article ends with suggestions for how teachers and teacher educators can infuse such theories into reflective, autoethnographic practices.
\end{abstract}

\section{Keywords}

case studies, civic responsibility, positioning theory, social justice, teacher identity 


\section{Introduction}

There are members of American society who are able to determinately argue that they have had experiences with injustice. Examples of poverty, racism, sexism, homophobia and abuse in our country are real, powerful and exigent, and they have created a group of people for whom discrimination and oppression are familiar phenomena. At the same time, there are individuals who claim sheltered upbringings and describe their worlds as generally normative and safe from the challenges that others must endure. While the former may tend to claim a conscious social justice teaching prerogative as a result of their own experiences, the latter may express reservations about their ability to teach towards ideals considered in the realm of justice. Finally, there are those who neither claim exclusive familiarity with injustice, nor shelter from it. These individuals might be seen seeking out exposure to inequities present in the world, learning from them by choice, and occasionally retreating from them when possible. This stance too would shape their identities as educators for social justice.

In this multi-case, qualitative study of beginning teachers, we seek to examine the varied deliberations teachers make when defining and negotiating their roles and responsibilities as social justice educators. Specifically, we tell the stories of three teachers who each assumed a different stance and we use their stories to suggest ways that their positions as social justice educators could grow and shift. Our overarching goal is to illustrate how all teachers can position themselves as advocates of justice.

Our work began with an understanding of the multiple ways teachers approach the complex endeavor of teaching for social justice. Even though all teachers participating in our study graduated from the same teacher education program in which discussions of marginalization, privilege, justice and injustice were the foundational mainstays of the curriculum, their individual articulations of who and why one is capable of teaching for social justice varied greatly. These variations were often tied to their personal histories and the ways in which they had experienced incidences of oppression. By drawing upon their narratives, we explore how the teachers view their ability and the ability of others to enact a justice-oriented education. Certain conceptual principles of teaching for social justice undergird our work. These include: (1) the importance of preserving multiple positions towards teaching for social justice; (2) the power of teachers reflecting on the strengths and limitations of their own positions; and (3) the responsibility of all to work toward social justice ideals and goals.

In our research with beginning teachers, we maintain a dual awareness of larger political and social structures, as well as an individual's unique location within these systems (Butler, 2003). Like Michelle Fine (1998), we argue that the 'self' is both politically situated and personally negotiated. This means that a social justice-oriented education must analyze systemic power and privilege while simultaneously acknowledging the idiosyncrasies of thought and experience. From this stance, multiple forms of oppression and privilege are examined as well as multiple responses to these conditions.

We hope that by exploring the multiple stances of those who teach for social justice, every educator can be embraced in his or her specific location of learning and that all can be regarded as responsible for working towards ideals of social justice. Of course, we do not seek to undermine the very real knowledge that emerges from experiences with injustice, nor do we wish to provide exemptions for those who regard themselves as detached and uninvolved. Rather, in the end, we hope to move practicing teachers, pre-service teachers, teacher educators and all those involved in the complicated pursuit of schooling to ask: How can teaching for social justice be conceptualized so that every individual may locate his or her position within it? 


\section{Conceptual groundwork}

To examine educators' varied perspectives on teaching for social justice, we look primarily towards positioning theory which attends to the ways individuals position themselves with respect to moral rights and duties (Barnes, 2004; Harre et al., 2009; Langenhove and Harre, 1999). This framework focuses on interpersonal relationships and examines how individuals assign roles for themselves and others, as well as the explicit and implicit reasoning they use when gauging civic action and moral responsibility. How one conceives of one's position is influenced by an evolving intersection of social beliefs, practices and personal experiences.

First applied in the social sciences by William Hollway (1984: 228), who described individuals' subjectivities as 'the product of their history of positioning in discourses', positioning theory is typically drawn upon to examine conflict situations from personal relationships to national disagreements (Sabat, 2001, 2008). For instance, Bronwyn Davies and Rom Harré (1990) provide an example of a sick woman and a man buying medicine at a pharmacy. When the medicine was found unavailable, the man apologized, 'I'm sorry to have dragged you all this way when you're not well.' This comment was construed differently by each party: the man saw himself as responsible for the woman's welfare while the woman found the apology an offensive display of the man's mastery over her. In one study on family and collective memory, Marga Kreckel (1981) demonstrated how a mother positioned herself as an authority over her sons and their spouses when recalling events of the previous weekend and so appropriated both the right and the duty to admit or refuse contributions to the collective telling of their family history.

Positioning theory can also be used to understand classroom interactions and events. As a principal analytical tool on a study of collaborative student learning in a senior mathematics classroom, Mary Barnes (2004) used positioning theory to identify a range of positions available to students during collaborative work. She explored how certain positions including the manager, the entertainer, the spokesperson or the outsider became accessible and delegated to certain students. Carol Linehan and John McCarthy (2000: 442) explained that in schools, 'both students and teachers have a degree of agency in how they position themselves in interactions but this agency is interlaced with the expectations and history of the community, the sense of "oughtness".' This sense of 'oughtness' constitutes what they call, 'local moral order'. We draw on these ideas when applying positioning theory to the field of education and examine how teachers position themselves and others as legitimate advocates for justice in the classroom.

As much as positioning theory allows us to better understand the manifold ways teachers presume responsibility within a justice-oriented educational framework, our work with teachers encouraged us to question how educators could establish new positions for themselves as advocates of justice. To this end, in conjunction with the analytical and explanatory potential of positioning theory, we also find the work of Sharon Todd (2003) particularly valuable in conceptualizing how to move beyond one's initially ascribed position. In Learning From the Other, Todd describes the process of learning as located within and created through encounters we have with another who is presumed to be exterior and different. In her work, the Other does not necessarily refer to those who occupy the margins of society but rather is that which is always outside of oneself, "what I myself am not' (2003: 3). The encounter we have with the Other introduces an ethical responsibility to listen, to regard multiplicity as a phenomenon which is epistemologically and pedagogically significant, and to maintain openness to this difference as a necessary pre-condition for learning. Indeed for Todd, education can be conceived as a relation with the Other as opposed to a farsighted or abstract consideration of curriculum and content. In the face of the Other, one is forced apart from a secure sense of knowing and is made vulnerable to a new understanding or meaning. 
Therefore, educators' positions as pursuers of social justice might readily shift in the face of encounters with those who are different from them; a claim that we suggest in this article.

\section{Methods}

This article's examination of teacher positioning draws from a larger qualitative study and graduate research seminar that focused on the ways new elementary school teachers, working with students ages 5-12, conceptualized social justice curricula and enacted them in their classrooms. We launched a multi-case study by asking: For beginning teachers who are committed to teaching for social justice, how does this commitment impact their classroom instruction?

We created a weekly research seminar to engage a small group of doctoral students in this effort. The four authors of this paper were part of the seminar's teaching team and an additional 12 students joined us as co-researchers. We knew that within the scope of one semester we would not be able to complete the study fully and chose to emphasize the processes of data collection and data analysis within the seminar. Before the semester began, we determined that the study would be centered upon multiple case studies of beginning teachers and each doctoral student would investigate the beliefs and practices of one beginning teacher.

Our research design involved classroom observations and teacher interviews and grew from our assumption that each teacher's experiences were unique. In particular, we understood that political understandings are the result of one's life story and social location, and that the teachers would articulate a wide range of beliefs about social justice. The graduates we studied were also working in schools with differing levels of racial and socio-economic diversity, mainly in urban settings, although one was a suburban school. We chose to collect and analyze case studies so that we could examine the 'local particulars' of each teacher's experience (Dyson and Genishi, 2005: 3).

An initial invitation was sent to all recent graduates of our college's preservice program for whom we had current emails and who were teaching in the New York City area. Employing purposeful sampling, we explained to all recipients our interest in examining how beginning teachers with a shared teacher education experience enacted curricula promoting social justice. In the end, 12 teachers agreed to participate and each was assigned a researcher who interviewed and observed that teacher enacting what she identified as teaching for social justice.

The first interview was designed to help researchers familiarize themselves with their participating teachers and to get a sense of their backgrounds and conceptions of social justice. Each researcher then conducted one to three observations in her participating teacher's classroom. The number of observations conducted in a teacher's classroom depended mainly on her availability and on the amount of time allotted to enacting justice-oriented lessons. The observations were followed by informal interviews in which the researcher asked the teacher to review her lesson and to explain its connection to social justice. The entire field-based research experience was concluded with an exit interview in which the teacher explained how her lessons reflected her conceptions of social justice and in which she outlined both the successes and hindrances that she experienced when doing this work. All of the interviews were audio-taped and the observations were documented in the researchers' fieldnotes. Researchers used a similar template and protocol to collect field notes and conduct interviews.

Reviewing our methods, we see the lack of consistency in observations as a potential limitation of the study, particularly as we received varying amount of data on each teacher. Yet, we also see value in the qualitative differences of the data we collected. 'The stories we tell' (Clandinin and Connelly, 2000: 17) are ultimately grounded in our relative positions and relationship with the notion of social justice. Similarly, ‘in angling one's vision' (Dyson and Genishi, 2005: 14) the 
decision of what one documents or does not obtain and/or the questions one asks may vary from one researcher to the other.

Next, from field notes and interview transcripts, each researcher created a narrative account of a classroom observation. The purpose of these narrative accounts was to retell and relive a curricular enactment, revealing the complexity and multiple layers behind each storied experience (Clandinin and Connelly, 2000). As a member check and a method of confirming that the vignettes accurately portrayed the teachers' words and curricular enactments, each narrative account was presented to the teacher participant. We approached our writing as 'tentative, always open to revision' (Clandinin and Connelly, 2000: 17), revising the vignettes based on the participants' suggestions and feedback.

After conducting our last revisions, we organized a dinner for the participants, performed a readers' theater composed of interview quotes, and presented them with a book of the group's lesson plans and vignettes. We felt that it was important that our research be of immediate benefit to the research participants and we saw the book, with its multiple examples of justice-oriented teaching, as a toolkit from which the teachers could draw inspiration and lesson ideas.

At the conclusion of that school year the four authors of this paper began coding the data using the strategies presented by Emerson et al. (1995). We read the data with a particular interest in understanding the relationships that teachers forged with the concept of social justice, what ideals they considered relevant to their roles as teachers, and the ambivalence with which new teachers struggled as they worked to teach for social justice. An emergent prevalent theme in the data related to how teachers used their personal experiences and backgrounds to leverage their intimacy with issues of social justice. We located different stances that participants occupied with regards to these issues, including responsibility, certainty or a lack of understanding. Most pertinent to our future analysis was our use of the codes 'legitimacy' or 'removal.' When using these codes, we defined legitimacy as the degree to which teachers expressed deeply rooted connections to issues of social justice, and we defined removed teachers as those who expressed a disconnect or distance from issues related to inequity and marginalization.

Committed to further pursuing this line of analysis, the four authors of this paper turned to positioning theory (Lagenhove and Harre, 1999; Barnes, 2004; Harre et al., 2009) to help us understand teachers' perceptions of their own responsibility to teach for social justice. This work helped us develop a more nuanced perspective of how teachers' positions were informed by their beliefs, practices and personal experiences. Furthermore, as we continued our analysis, we saw the terms, legitimate and removed as limiting and found that teachers' actual stories were more complex. Rereading the teachers' cases pushed us to move past this binary as these terms did not seem to parallel the spectrum of positions we were observing. Our analytic trajectory was an example of what Valerie Janesick (1994) described as the dance of qualitative research. In the qualitative dance, researchers may continue to reread and draw upon data in different ways. They repeatedly return to the data and may find negative examples in previous understandings that call into question previously utilized schema.

The three cases highlighted in this paper were specifically spotlighted because of the ways they illustrate the multiple positions that teachers may assume. They collectively illustrate the different ways that teachers frame their responsibilities and their ability to impart a justice-infused curriculum. We draw from stories of their personal backgrounds including accounts from their childhood or adolescence, experiences from their teacher education program, and examples of their teaching to explain their multiple positions. Ultimately, we chose these cases because we believe that they vary in ways that are interesting and instructive. We believe that this variation will be useful to 
readers as they consider the different assumptions and footing that teachers' adopt with regards to their abilities to teach for social justice.

\section{Teacher stories}

In what follows, we present case studies that illustrate how three teachers differentially positioned their qualifications to teach a social justice-oriented curriculum. As we tell these stories, we demonstrate how teachers refer to their knowledge and experience as qualifying determinants of social responsibility and we hope to show how such declarations exclude some from not only seeing their complicity, but also in sharing justice-oriented work. Following the presentation of the teachers' stories, we discuss how the concept of the Other (Todd, 2003) may allow greater fluidity along this range of self-proclaimed social justice responsibilities.

\section{Lucy}

Lucy's dedication to teaching for social justice appeared deliberate and resolute from the beginning. As a Black woman and a child of Haitian immigrants, she identified as having a first-hand understanding of prejudice. In an interview she said, 'If I walk down the street, if a White person looks at me funny, I'm not going to think there's a booger in my nose. First thing I'm going to think is, it's cause I'm Black.' She tied her deep commitment to issues of rights and justice to this heightened awareness of her own marginalization, implying that her history of oppression rendered her uniquely attuned to these issues and exceptionally capable of imparting them to her students.

Lucy also suggested that she was more capable than others of enacting such a curriculum. Her preservice program consisted of mostly White, middle-class students and during an interview she described a classmate who admitted to having been raised in a prejudiced environment. When that student was later placed in predominantly Black school for student teaching, Lucy was doubtful of her ability to effectively teach a justice-oriented curriculum, particularly in this setting. She remarked, 'she had a lot of growing up to do ... She might have needed another year ... she needed a lot more change.' Here we see that Lucy was skeptical of those teachers who she felt did not understand the challenges of discrimination and oppression, and she doubted their ability to adequately address issues related to social justice.

Because so few of her classmates had experienced discrimination firsthand, Lucy commented that she was often charged with the task of explaining the impact of racism and describing the enormous role that it had played in her life. She described the irritation she felt when she encountered classmates who felt that their teacher education courses were too focused on issues of racism. 'Until people realize what's going on, we can't come up with a solution. We're saying everything's all great now and just last year somebody called me a n---.' The assumption that Lucy knew more about racism due to her identity as a non-White member of American society was a position she not only keenly perceived but one she strategically either resisted or accepted, sometimes simultaneously.

As a teacher, Lucy was determined to directly approach topics such as discrimination and to ensure that her students were capable of navigating an unjust and often unfair society. She taught 5th grade in a school with a bilingual curriculum that served deaf and hearing impaired students as well as those without hearing impairments. She co-taught her class with Aaron, a White man who is deaf, and together they emphasized the reality of structural inequalities and tied their students' deafness to other forms of discrimination such as racism and classism. Lucy felt that she was in a unique position to understand her students' plight and as such positioned herself as particularly 
suited to the role of advocate and purveyor of a justice-oriented curriculum. In describing the stance she and Aaron had adopted, she stated:

We talk about rights all the time and responsibility and respect. We have a lot of discussions and I ask them if they have any experiences not being treated fairly and I tell them my own experiences and Aaron does, too. We just tell them our own experiences and we just have discussions through that.

Because of their experiences with oppression, Lucy positioned herself and Aaron as exceptionally quakified, as well as morally obligated, to teach these types of lessons and in turn, attempted to created a robust social justice curriculum that included a unit on slavery and a service project designed to raise money for the homeless.

Lucy also distinguished herself from teachers in her school whom she positioned as unqualified or unwilling to enact justice-oriented curricula. When asked whether colleagues at her school taught about discrimination, she responded,

Honestly? No. I can see one teacher doing that. Maybe two. And it's sad to say ... they're Black. Me and Aaron we click so well because he's been through so much stuff. I've been through so much stuff. And, I get him, he gets me because of all those different kinds of discrimination ... So, I would see deaf teachers doing it. I see some of them doing it, but I don't see the other team teacher doing it.

She observed that only those teachers who were Black or deaf made a point to include these issues in their curriculum and she expressed frustration at the idea that just a few teachers should be made entirely responsible for teaching about oppression at her school.

There is no doubt that Lucy's own history of injustice endowed her with an exceptional cultural competence (Ladson-Billings, 2001) that helped to establish a sense of camaraderie and common purpose in her classroom, positioning her students as crucial co-participants in the struggle toward justice. Moreover, her ability to justify her decisions to teach for social justice ensured that necessary conversations about power and privilege would be raised in her classroom. In a qualitative study on raced consciousness, Anne Ruggles Gere, Jennifer Buehler, Christian Dallavis and Victoria Shaw Haviland (2009) observed that preservice teachers who were members of marginalized groups tended to view themselves as more culturally competent than their White, middle-class counterparts. Moreover, 'African American applicants identified with students in high-need schools in ways that their White peers did not' (Gere et al., 2009: 821). Like participants in that study, Lucy displayed a surety that allowed her to tackle issues of oppression, injustice, and social accountability, topics which some teachers might avoid.

Yet, while Lucy's sense of moral responsibility was certainly laudable, we must also examine the ways in which her sense of self may have curtailed, rather than advanced, the very principles that she sought to impart. For example, Lucy's tendency to align her students' oppression with her own may have diminished the specificity of their particular struggles. If she were to instead acknowledge that her own experiences were separate from those of her deaf students, she might better learn from those students and help them to pinpoint their unique encounters with prejudice. So too, Lucy's tendency to tie past experiences of marginalization to one's ability to enact a social justice curriculum may create undue limits upon those who have not had such experience. This may lead her to disqualify colleagues despite their potential to contribute to the struggle for equity. As Todd (2003) pointed out, important forms of learning and teaching occur when we are open to the Other as different and capable, when we embrace multiplicity as generative. We might therefore imagine Lucy positioning herself and others differently. Instead of viewing her peers as incapable of teaching for social justice, Lucy might position herself as interested in learning from those 
whose lives may have been more 'sheltered'. She might forge new ways of approaching issues of injustice that uplift others' degrees of capacity and see their viewpoints and actions as critical.

\section{Jennifer}

In contrast to Lucy, Jennifer expressed a detachment from injustice that led to feelings of incapacitation and ineptitude with regards to her ability to teach for social justice. While Lucy positioned herself as particularly justified to teach justice oriented ideals in the classroom, Jennifer positioned herself as disconnected, questioning both her understanding of and ability to translate justice-oriented ideals into her practice. Jennifer was raised in a White homogenous community, a context she felt offered her little exposure to diversity. Describing her upbringing, Jennifer explained, 'It's just a small town culture where a lot of people just want to maintain their way of being.' She found her 'sheltered' upbringing segregated her from issues she considered related to social justice and these disconnected feelings led her to question her preparedness as a teacher.

It was through her urban teacher education program that Jennifer first engaged in conversations with individuals who were racially and ethnically different from her. In an interview, Jennifer explained that while she identified with the White, blond characters often represented in popular books she read as a child, including Sweet Valley High (Pascal, 1984), she did not realize until her graduate school experience that other racial groups in American society lacked representation in curricular texts and materials. It was through her discussions with colleagues that Jennifer became aware of 'other ways of being' and described this perspective-altering experience as, 'such an eyeopener in realizing how naïve I am as a result of my upbringing.' Jennifer's experiences in her teacher preparation program thus prompted both excitement and insecurity. They raised her awareness of multiple perspectives, but they also triggered feelings of anxiety, leading her to label herself as 'naïve'.

Further reflections on her teacher education program illustrated her feeling that she was unprepared to work with a diverse student body. For example, she recollected an incident when a question was raised about how to respond to a Jehovah's Witness student during school holidays:

We talked about things in our class and I hadn't experienced them. I think it was a child who has a parent who is a Jehovah's Witness and how do you navigate that when you have holidays or stuff ... and I was listening but I wasn't able to take it in because I hadn't had that [exposure] ... it's not in [my] zone of proximal development.

In this excerpt, one can see how Jennifer perceived herself as unable to understand and comprehend what she deemed as different or outside of her monocultural upbringing.

Interestingly, Jennifer returned to teach 1 st grade in a context that resembled the one she grew up in - where 'most of the kids are White if not blond' - and worked to create change. While she described the community as 'so saturated in their culture and way of life ... that there is an unwillingness to listen to other view points and accept other ways of being', she hoped to provide students with opportunities to learn about cultures and traditions outside of their environment. Jennifer went to the library every weekend to find books that represented cultures that did not necessarily reflect the experiences of her students. For example, Jennifer shared a picture book with her students about the people and traditions of India. Jennifer hoped that these books would extend the discussion 'into different times and places and new and unheard of worlds' (Ayers, 2001: 65), a curricular move she perceived as social justice oriented. She worked to find literature 
that balanced what she labeled 'mirrors', the Dick and Jane books she received for Christmas from her students' parents, and 'windows', those with characters who represented life outside of the school's White, middle-class context. While mirrors reflect one's own life and experiences, windows offer views of worlds where students may see a variety of differences (Bothelo and Rudman, 2009).

As an example of her social justice teaching, Jennifer shared her read aloud of Fly Away Home (Bunting, 1991), a story of a young boy who lives with his father in an airport because they cannot afford to have a home of their own. After reading the book, she asked her students, 'Is it fair that Andrew and his father are living in an airport?' Jennifer hoped this conversation would lead into a discussion about fairness, focusing on the idea that 'things should be fair and if they are not fair, you make them fair'. Yet, Jennifer abruptly ended the lesson. She admitted feeling worried about what students may say, explaining during the exit interview, 'I didn't really know where it would go'. Here, Jennifer acknowledged her insecurity and fear of facilitating discussions about topics that she may not be able to respond to or control.

Even with her attempts to enact justice-oriented lessons, Jennifer expressed a naïveté with regards to conversations about power and injustice. When asked to articulate her conceptions around social justice as a teaching framework, comments such as, 'I am not understanding what I am thinking of all of this', were documented at least three times throughout the interview. Furthermore, when Jennifer was asked about which social justice issues she considered both nationally and globally urgent, Jennifer commented, 'I feel uncomfortable trying to speak from a position of authority on this, because I feel like I really don't know yet ... I am still grappling. This is where I am now and I am not really ready to expand and think about the higher things now 'cause I'm so new at everything.' Prevalent through the interviews was Jennifer's hesitancy and dismissal to claim an understanding of social justice issues.

When capturing an overview of Jennifer's work as a teacher for social justice, there are notable areas of strength. Jennifer attempted to expose her students to stories that portrayed life experiences that she believed were not seen in their community. Specifically, the books in her classroom library as well as her spotlighted read aloud demonstrate her commitment to raising conversations about diversity and fairness. It seemed that Jennifer's curricular moves were an effort on her part to develop pedagogy that integrated multiple perspectives and disrupted the form of education that she herself had experienced.

However, her position as a social justice educator was also limited. From Jennifer's perspective, her lived history curtailed her participation in social transformation. She questioned not only her ability to translate social justice ideals into the classroom, but her authority to be a social justice educator. In claiming ignorance or ambiguity, Matthews and Dilworth (2008: 383) argue that such 'dispositions can block, restrict, or denigrate the use of transformative academic knowledge and critical consciousness-raising'. Jennifer's decision to position herself in this way may have been compounded by declarations made by educators similar to Lucy, who push those considered 'detached' even further into the margins.

Yet, by challenging her own understandings and by learning from teachers like Lucy who have experienced discrimination firsthand, Jennifer might begin to imagine herself as responsible for teaching about injustice. Moreover, she might acknowledge the justice-oriented learning she is already promoting and expand her view of her own personal and teaching experiences as wholly valid and noteworthy, using them as entry points into a growing social justice curriculum. Naming what is unknown and fearful can become fruitful beginning steps toward reflective practices. 


\section{Allison}

In the last two vignettes, we presented Lucy, a teacher with self-proclaimed credentials and responsibility to teach for social justice, and Jennifer, who approached issues of social justice with hesitation Here, we use the case of Allison to illustrate a third position, as Allison uniquely chooses to embrace, and subsequently struggle with the responsibilities of teaching for social justice. With a natural penchant for diversity that began as a child, she actively pursued a justiceoriented teaching agenda that she saw as essential and simultaneously challenging.

Allison, a White woman, was reared within a White, middle-class suburban town, a site that originally inspired her search for individuality and diversity. In an interview, she admitted: 'I always felt that I didn't belong ... I didn't fit into a group of kids and then I wasn't really interested in a lot of things that other kids were interested in, like sports.' Intentionally positioning herself as distant and different from her peers, she elected to embrace her uniqueness. She explained: 'I started defining myself and being different from other people. I went through that stage that a lot of people go through. "I am different from you!" She saw a dedication to the arts, which followed her through college, as reflecting this intent and she attributed individuality as a mainstay of her adolescence and young adulthood.

Allison admitted to feeling self-conscious of the fact that she had 'never been anywhere' and so, as an exercise of her independence, planned a trip to Japan. In looking back, she felt that this trip made her 'sensitive and aware' of difference. One example of what Allison came to appreciate as 'nuances of culture' involved the etiquette of not making eye-contact. She explained, 'If somebody doesn't make eye contact with you, that means that they're a liar or too shy or not confident in our culture, and in Japan, that just means you're polite.' Through this encounter with difference, she confirmed that there is 'not just a truth about human beings'. Acknowledging this absence of one truth, Allison was able to see the world as composed of great diversity that should be affirmed (Nieto, 1994).

In speaking of her teacher education program, she appreciated the ways in which professors supported her exploration of diversity. She praised one assignment that asked the preservice teachers to 'talk about your biases ... to be aware and sensitive to that'. She also highlighted a pivotal text called A Different Mirror by Ronald Takaki (1993) which detailed the history of the USA 'but from multiple perspectives'. She viewed these experiences as affirming her interest in diverse perspectives and critical to her development as a social justice educator.

Reflecting her childhood and young adulthood experiences with diversity, Allison aimed to craft a curriculum that honored all the forms of difference in society. At the time of our study, she was working as a 5 th grade teacher in a school attended by a student body of diverse racial and socioeconomic backgrounds and a staff committed to continuously asking 'how we can really honor diversity in our student body'. Therefore, she had reason to believe that her commitment to affirming diversity would be welcome in the school context.

Specifically during this research, Allison was using The Watsons Go To Birmingham - 1963 (Curtis, 1995) to teach about stereotypes. She described what attracted her to the book:

It's set in 1953, the civil rights era. There are clearly a lot of stereotypes ... It's not just that White people are prejudiced against everybody, but it's like the Black people have prejudices too. And, it's not just Black/ White. There are people of Hispanic descent There are Asian people in the city that they're living in.

Allison appreciated how the book illustrated forms of prejudice that exist in society and the presence of multiple ethnic and racial groups. Pointing out the different prejudices that people harbor, as well as the diverse nature of the portrayed city, may help students think about what promotes and 
hinders generative engagement with others. While much of school curriculum offers 'no help in understanding the continuation of inequities and injustice in their (or others') society' (Levstik, 2000: 290), Allison wanted to enact a curriculum that brought light to inequities and prejudices that have lingered long after the civil rights era. After examining stereotypes through the text, she planned to ask the students 'What are the stereotypes you have?' a question she thought was 'really powerful' and aligned with her overall purpose of 'trying to genuinely create a feeling of open mindedness'. Allison hoped to teach for social justice by asking students to reflect upon their own biases, acknowledging that each individual carries her own ways of seeing the world.

While Allison was committed to promoting dialogue about race and other aspects of social and political identity, she also named her uncertainties about this type of teaching.

If you really want to have a democratic classroom and have people have different opinions, then isn't it okay for a student to have some strong opinions about another race or something that I personally would get really upset to hear? ... Is it okay to have that conversation?

Here, Allison noted a curious implication of raising conversations about topics that some might consider controversial. She spoke of vacillating between the excitement inherent in airing 'different opinions' and the discomfort of hearing student opinions she considers problematic. Allison was also concerned about expressing her own opinions. She wondered 'how much to talk about, with all the issues that there are', including those she considered pressing such as homophobia or the connection between academic achievement and socioeconomics. She wished to encourage her 5 th graders to engage in talk about social and political issues, but she also questioned the weight of her own voice as well as her ability to connect with certain student view points.

Allison's position, as one who deliberately questions and pursues diverse experiences and as one who teaches for social justice, may be seen as inspiring. She spoke of the learning supported by her trip to Japan and her teacher education program. She also clearly recounted the ways in which she folded the ideals of affirming diversity and naming prejudices into her work with students. Finally, she raised important questions about her teaching practice, suggesting her recognition that teaching for social justice is an enduring struggle with no pedagogical certainty. Ultimately, we see Allison as unsure of aspects of her pedagogy yet connected enough to see her place as a justice-minded educator. Her ability to speak with clarity about teaching for social justice and take on new questions about this process suggests that she was an intentional, wellsituated learner.

As with the other spotlighted cases, Allison's position might grow more malleable, and she might expand her sense of responsibility as an educator for social justice. Allison's position can be framed as one that was self-assumed or assumed through choice. In her hometown, she chose to position herself as different and then pursued a similar path in her decision to travel to Japan. She exposed herself to experiences that may have induced discomfort and she was now able to use those same tools to develop a pedagogy that emphasized diversity and grappled with difficult questions. How might Allison re-imagine her positioning if she experienced injustice and diversity not as a choice, but as an imposed and even uncomfortable aspect of being in society? Having not experienced discrimination in the way that Lucy had, nor a sheltered young-adulthood like Jennifer, Allison may be able to learn from others whose decisions to teach or not teach for social justice seem more obvious and less of a choice. Specifically, this learning could lead Allison to assume a new stance of urgency similar to Lucy's. Likewise, she might emulate Jennifer's clarity about the gaps in her own development, thereby sharing her belief that one must constantly strive toward social justice ideals, even if those ideals may never be fully realized. 


\section{Forging ahead: beyond singular positions}

Three distinct yet fluid categories emerged when we analyzed the ways that these teachers articulated their ability to understand and teach for social justice: a justification of action; a disconnection from oppression; and an intentional, yet voluntary, search for difference. In using positioning theory to map the making and remaking of moral responsibility, we argue that each position is based on human constructions and relationally constituted. The positions reflect worldviews that bend not only with social events, situations and phenomena, but also with our embedded conceptions of allies and opponents. While each position carries fruitful possibilities, it is simultaneously limited. We see that solidarity is caught by exclusion; freedom potentially breeds inactivity; and the privilege to choose can make engagement with injustice a matter of self-determination rather than an imperative.

If we believe in the power of collective struggle and the necessary participation of all members from every rung on the social ladder, then this study speaks to the importance of detaching prior experience as the sole indicator of capability. Capability is also engendered through our interactions with others. 'We are', in the words of Elizabeth Heilman (2007: 89), 'all composed of others; we all are made up of others from the inside out'. Positioning theory is thus framed as a social practice through which meaning is made and transformed (Vanderstraeten and Beista, 2006). It is the social character of education rather than the social characters themselves that lends itself to changes in individual perception. While each of the teachers in this study clearly bears her own idiosyncratic view, their divergent standpoints are built upon and constituted by their dynamic relationship to those different from themselves.

We argue that these relationships with difference can further grow when encounters with the Other are actively pursued. As a pre-condition for this type of education, the Other must be perceived and encountered as always exterior to the self, yet in a relationship that is mutually constitutive. For this reason, we assert here that subjective differences are what matter, for it is precisely the infinite differences that one 'sees' in an encounter that allows for learning to occur and it is precisely these disjunctures, slippages and incommensurabilities that must be preserved and cherished. These are not obstacles to education but rather the very core at which education is borne. While positioning theory can be helpful in acknowledging how social context affects personal histories, preferences and capabilities (Barnes, 2004), Todd suggests a return to the encounter itself in order to establish an ontological sense of ethical responsibility presumed to be for all and by all. We believe that this perspective on the social relationship of educative practice can move individuals to be morally responsible for one another as a friend, foe, family or foreigner.

\section{Thoughts for teachers and teacher educators}

Eliciting histories - as we did in our study with beginning teachers - has the potential to invoke a radical sense of learning wherein individuals connect their ways of being to the larger social world as well as to each other. As a reflective practice, autoethnographic work (Denzin, 1997; Miller, 2005; Anderson, 2006) asks teachers and teacher educators to deliberately analyze how the act of positioning arises through life circumstances and to then explore the possibilities of reimagining human interconnection as more inclusive and compassionate.

In this section, we consider how such autoethnographic work can be taken up by educators, illustrating what this study on social justice and beginning teacher responsibility may offer to those who dream of 'a world that is caring, loving and truly compassionate; a world that honors healing' (Denzin and Giardina, 2009: 12). At its most basic level, this research provides a framework for 
understanding the varying positions that teachers assume with regards to their confidence and capability as social justice educators. While in one study, researchers found raced consciousness to greatly influence how preservice teachers positioned themselves (Gere et al., 2009), this work showed that while race was a predominant factor in deciding legitimacy, other criteria such as nationality, disability, political affiliation and exposure to cultural difference were seen as similarly valid credentials of experience. This signifies that teachers draw from multiple vantage points in their efforts to understand injustice and that they attempt to engage the concept through their own worlds.

Teachers' points of entry to the endeavor of teaching for social justice are not, and will never be, considered of equal value. This would deny the realities of ideological and structural power that privilege certain individuals at the expense of others. Nonetheless, teachers and teacher educators might use the explanatory power of positioning theory to understand, reflect, and move forward from rigid notions of social responsibility.

If teacher beliefs about teaching for social justice are explained through prior experiences and processes of identity-making, autoethnographic methodologies may help design classroom practices that allow for self-conscious introspection and a better understanding of self and others. As outlined by Leon Anderson (2006: 384):

Autoethnographers should illustrate analytic insights through recounting their own experiences and thoughts as well as those of others. Furthermore, they should openly discuss changes in their beliefs and relationships over the course of fieldwork, thus vividly revealing themselves as people grappling with issues relevant to membership and participation in fluid rather than static social worlds.

Expository and dialogic practices that ask teachers to articulate their place within justice-driven education may encourage reflection on ideas of membership and commitment. This may in turn loosen preconceived assumptions and prejudiced beliefs about who is capable of teaching for justice.

With deliberate focus placed on why teachers embrace certain positions of moral responsibility, such reflective work can also transform competitions of experience into encounters of trust, learning and listening. Teachers may reflect upon their 'own perspectives, beliefs, and life worlds in conjunction with, in comparison with, and in contrast to their students' and their students' communities' (Milner, 2006: 356). This relational reflection, where the juxtaposition of multiple voices opens opportunities for learning, encourages teachers to honor difference, admit to limitations and seek that which is unknown or unfamiliar. This requires a careful position of openness, anchored to the experiences of others while staying mindful of the connection between biography and social structure. Such work can serve as pivot points for teachers from all social circumstances to come together, in dialogic fashion, with the imperative to preserve and learn from difference (Todd, 2003).

In the end, we emphasize that positions of social responsibility must be rendered malleable and incomplete and we affirm the importance of acknowledging the Other as a part of the work of justice teaching. We hope for all teachers, including Lucy, Jennifer and Allison, to see their justiceoriented positions as expansive: constantly moving, shifting, evolving and yet-to-be. Justice in a divisive world cannot succeed unless we transcend the constraints of our own constructed limitations. When borders are drawn and responsibilities delegated, voices become inevitably silenced and the necessary involvement of all is threatened. Some hope to be exempt from responsibility, while others wish to be heard in their demands for honor and dignity. Along this spectrum are myriad others who continue in their work as social justice educators. Imagine the possibility of 
framing all individuals as inevitably tied to the concept of social justice, as singular narratives of a grander story, as all taking action no matter how far away or intimate the tribulations of injustice may seem.

\section{References}

Anderson L (2006) Analytic autoethnography. Journal of Contemporary Ethnography 35(4): 373-395.

Ayers W (2001) To Teach: The journey of a Teacher. New York: Teachers College Press.

Barnes M (2004) The use of positioning theory in studying student participation in collaborative learning activities. Paper presented at the Annual Meeting of the Australian Association for Research in Education.

Bothelo M and Rudman M (2009) Critical Multicultural Analysis of Children's Literature: Mirrors, Windows, and Doors. New York: Routledge.

Butler J (2003) The question of social transformation. In: Beck-Gernsheim E, Butler J, Puigvert L, et al. (eds) Women and Social Transformation. New York: Peter Lang.

Bunting E (1991) Fly Away Home. New York: Houghton Mifflin Company.

Clandinin J and Connelly M (2000) Narrative Inquiry: Experience and Story in Qualitative Research. San Francisco, CA: Jossey-Bass.

Curtis CP (1995) The Watsons go to Birmingham - 1963. New York: Yearling.

Denzin N (1997) Interpretive Ethnography: Ethnographic Practices for the 21st Century. Thousand Oaks, CA: SAGE.

Denzin N and Giardina M (2009) Qualitative inquiry and social justice: towards a politics of hope. In: Denzin N and Giardina M (eds) Qualitative Inquiry and Social Justice. Walnut Creek, CA: Left Coast Press, 11-52.

Dyson A and Genishi C (2005) On the Case: Approaches to Language and Literacy Research. New York: Teachers College Press.

Emerson RM, Fretz RI and Shaw LL (1995) Writing Ethnographic Fieldnotes. Chicago, IL: The University of Chicago Press.

Fine M (1998) Working the hyphens: reinventing the self and other in qualitative research. In: Denzin NK and Lincoln YS (eds) The Landscape of Qualitative Research, 1st edn. Thousand Oaks, CA: SAGE, 130-155.

Gere AR, Buehler J, Dallavis C, et al. (2009) A visibility project: learning to see how preservice teachers take up culturally responsive pedagogy. American Educational Research Journal 46(3): 816-852.

Harre R, Moghaddam F, Cairnie TP, et al. (2009) Recent advances in positioning theory. Theory \& Psychology 19(5): 5-31.

Heilman E (2007) (Dis)locating imaginative and ethical aims of global education. In: Roth K and Gur-Ze'ev I (eds) Education in the Era of Globalization. Dordrecht, The Netherlands: Springer, 83-104.

Janesick VJ (1994) The dance of qualitative research: metaphor, methdolatry, and meaning. In: Denzin NL and Lincoln YS (eds) Handbook of Qualitative Research. Thousand Oaks, CA: SAGE, 209-219.

Ladson-Billings (2001) Crossing Over to Canaan: The Journey of New Teachers in Diverse Classrooms. San Francisco, CA: Jossey-Bass.

Langenhove L and Harre R (1999) Introducing positioning theory. In: Harre R and Langenhove L (eds) Positioning Theory. Malden, MA: Blackwell, 14-31.

Levstik LS (2000) Articulating the silences: teachers' and adolescents' conceptions of historical significance. In: Stearns PN, Seixas P and Wineburg S (eds) Knowing, Teaching, and Learning History. New York: New York University Press, 284-305.

Matthews S and Dilworth PP (2008) Case studies of preservice teachers' ideas about the role of multicultural citizenship education in Social Studies. Theory and Research in Social Education 36(4): 356-390.

Miller, J.L. (2005) Sounds of Silence Breaking. New York: Peter Lang Publishing.

Milner, HR (2006) Preservice teachers' learning about cultural and racial diversity: implications for urban education. Urban Education 41(4): 343-375.

Nieto S (1994) Affirmation, solidarity and critique: moving beyond tolerance in education. Multicultural Magazine 1(4): 9-12.

Pascal F (1984) Sweet Valley High. New York: Randomhouse. 
Sabat SR (2001) The Experience of Alzheimer's. Oxford: Blackwell.

Takaki R (1993) A Different Mirror: A History of Multicultural America. New York: Back Bay.

Thompson A (1997) For: anti-racist education. Curriculum Inquiry 27(1): 7-44.

Todd S (2002) Listening to attending to the 'Echo of the Otherwise': on suffering, justice, and education. Philosophy of Education Yearbook 405-412.

Todd S (2003) Learning From the Other: Levinas, Psychoanalysis, and Ethical Possibilities in Education. Albany, NY: State University of New York Press.

Vanderstraeten R and Biesta G (2006) How is education possible? Pragmatism, communication, and the social organisation of education. British Journal of Educational Studies 54(2): 160-174. 